\title{
A cultura cinematográfica nas exposições universais: modernidade e tradição na Paris de $1925^{1}$
}

\author{
Eduardo Victorio Morettin
}

Resumo: $\mathrm{O}$ artigo pretende analisar a presença do cinema na Exposition Internationale des Arts Décoratifs et Industriels Modernes, realizada em Paris em 1925. Na década de 1920, consolidando-se como meio de comunicação de massa, ele passou a ser utilizado cada vez mais como "vitrine" em que a nação projetava as virtudes nacionais a serem celebradas em um cenário marcado pela corrida imperialista. Neste caso específico, os discursos da modernidade e da tradição conciliaram-se a fim de celebrar o caráter nacional francês dentro de um quadro marcado pela afirmação cultural do cinema.

Palavras-chave: cinema e história; história do cinema; exposições universais.

Abstract: Film culture in the world exhibitions: modernity and tradition in the Paris of $\mathbf{1 9 2 5}$ - This paper analyzes the participation of the cinema in Exposition Internationale des Arts Décoratifs et Industriels Modernes held in Paris in 1925. Since the 1920s, by establishing itself as a means of mass communication, cinema has served more and more as a "showcase" in which the nation could project national virtues to be celebrated in a scenario marked by the imperialist race. In this particular case, the discourses of modernity and tradition reconciled themselves to celebrate the French national character within a framework of growing cultural affirmation of the cinema.

Key words: film and history; film history; world's fair.

\footnotetext{
"uma exposição é, antes de tudo, um grande espetáculo" General Marcel Olivier, Delegado Geral da Exposição Colonial de 1931
}

1 Pesquisa desenvolvida com o apoio do CNPq. 
Uma observação de caráter geral, anterior a um comentário mais específico sobre a Exposition Internationale des Arts Décoratifs et Industriels Modernes, realizada em Paris em 1925, relaciona-se ao lugar que a cultura ocupou dentro das exposições universais sediadas na França ou que contaram com sua participação.

A convergência entre arte e indústria nestas exposições esteve presente desde o início da história destes eventos. Na concorrência com Alemanha e Inglaterra, a França já no século XIX indicava a dimensão cultural e estética como um dado singular, próprio de suas características nacionais e como elemento diferenciador em relação às outras potências. Léon de Laborde, um dos comissários na The Great Exhibition of the Works of Industry of all Nations (Londres, 1851), a propósito do que deveria ser feito pelos franceses para se distinguir nesta disputa, afirmava que caberia, "diante de nossos rivais ingleses, procurar uma originalidade e uma superioridade", qual seja, a de ressaltar "a importância do elemento estético em nossa produção nacional", indicando "na penetração da técnica e da estética, da arte e da indústria, o princípio de uma magnífica renovação de nossas artes decorativas" (apud HUHN, 1987, p. 392 - 393). Esse princípio, o da valorização do elemento estético aliado à dimensão industrial, será importante para pensarmos o lugar do cinema na exposição de 1925.

\section{A Exposição Internacional de 1925 e a presença do modernismo}

A Exposition Internationale des Arts Décoratifs et Industriels Modernes de 1925, que teve Paris como palco, ilustra "a pesquisa de uma nova arte de viver e, nos antípodas, a revolta dos surrealistas" (MANIER, 2006, p.6). A capital francesa era, naqueles anos, o ponto de reunião de diferentes correntes artísticas, como o dadaísmo, o surrealismo e o cubismo, que encontraram no cinema um meio de expressão em sintonia com a perspectiva de valorização da máquina, como foram os casos de Entr'acte (1924), de René Clair, e Ballet Mécanique (1924), de Fernand Léger². Cabe lembrar que, em outubro de 1924, o manifesto surrealista escrito por André Breton veio a público e determinou um dos elementos que nos ajudam a contextualizar a Exposição de 1925 e o lugar do cinema moderno no evento.

Ao mesmo tempo, a Paris do pós-guerra vivia um processo de intensa urbanização, indicando uma mudança de orientação nas formas de viver de um país com forte tradição rural. Nesse compasso, projetos de intervenção urbanística foram concluídos ou idealizados, como a inauguração em 1925 da Cité Universitaire. Nesse cenário voltado à valorização do consumo, da moda e do luxo, a butique era "um meio chave da restauração após-guerra e um componente da renovação urbana" (MANIER, 2006, p. 13).

A Exposição de 1925 abrigou mais de 150 pavilhões, galerias e edificações, a maioria inaugurada quando de sua abertura, em 25 de abril. Não contou com a participação

2 O surrealismo no cinema somente ecoou apenas em 1929, com Le Chien Andalou, de Luís Buñuel. 
da Alemanha e dos Estados Unidos, mas teve a presença, pela primeira vez em evento deste tipo, da União Soviética.

A arquitetura moderna era exceção no interior do espaço expositivo. Mesmo ocupando um papel minoritário, do ponto de vista quantitativo pelo menos, seus pavilhões provocaram fortes reações. Dentre os arquitetos em busca de formatos pautados por outra racionalidade e uso de materiais, encontramos: Kostantin Melnikov, autor do pavilhão soviético; Le Corbusier, idealizador do pavilhão L'Esprit Nouveau, que incluiu em seu projeto pinturas de Juan Gris e Amédée Ozenfant, além de duas esculturas de Jacques Lipchitz e pinturas murais de Fernand Léger; e Robert Mallet-Stevens ${ }^{3}$, responsável pelo pavilhão do Turismo, um dos halls da Embaixada Francesa, cuja ornamentação ficou a cargo de Robert Delaunay e Fernand Léger, e o jardim da Habitação Moderna, "onde se encontravam as famosas árvores cubistas em concreto dos irmãos Martel" (BRÉON, 2006, p.26).

O pavilhão de Melnikov, por exemplo, foi entendido como a expressão mesma do que era a União Soviética de então: "pesquisa de novas formas, economia espacial, utilização de materiais mais simples, construção racional, ausência do supérfluo, ignorância do barroco, negligência total da ornamentação inútil, etc." (ROMOFF, 1925, p. 125).

Além da arquitetura, tiveram forte ressonância: o teatro e, dentre os seus principais expoentes, Vsevolod Meyerhold, diretor e ator, responsável pelo método conhecido como biomecânica, de forte influência em Sergei Eisenstein, seu aluno e discípulo (ver OLIVEIRA, 2008, p. 1 -20) ${ }^{4}$; a escultura, comVladimirTatline e o seu projeto de monumento à Terceira Internacional; e as chamadas artes gráficas, com Alexander Rodtchenko, figura que teve grande destaque no evento parisiense.

Rodtchenko participou da exposição de diferentes maneiras. Foi o criador do Clube Operário, um dos estandes do pavilhão soviético, e o responsável pela organização, dentre outras seções, da Seção de Artes Gráficas e Cartaz. Além disso, suas fotos-montagem, cartazes de cinema e gravuras estavam espalhadas pelos diferentes espaços da exposição. Por fim, integrou o júri de admissão (EXPOSITION, 1925, p. 99 e seguintes).

A participação restrita da arte moderna, exemplificada aqui pelos exemplos dados acima, ligava-se, para além da reação solidamente fincada na tradição, à própria concepção norteadora da exposição, dedicada a celebrar as Artes Decorativas e sua união com a indústria. Como diz Marcel Magne, professor do Conservatoire National des Arts et Métiers e consultor técnico do Comissariado Geral da Exposição de 1925, em conferência proferida em um dos congressos que ocorreram durante o evento, a tradição não deveria ser esquecida, como aconteceu em 1900:

3 Mallet-Stevens era, então, um dos principais nomes da arquitetura francesa, tendo sido na década de 1910 um dos primeiros a reagir contra o ecletismo reinante. Concebeu também móveis e objetos recorrendo a materiais novos, como o metal. Em 1924, foi o responsável pelos cenários de L'Inhumaine, filme de Marcel L’Herbier, que comentaremos a seguir. Ele também organizou no mesmo ano, junto com Léon Moussinac, a exposição 'L'art dans le cinéma français', ocorrida no Musée Galliera, que, para Isabelle Marionone, prefigura e antecipa a Exposição de 1925. Foi em 1930 o presidente da Union des Artistes Modernes (BRUHAMMER, 1966, p. 23 - 24 e 50 e MARIONONE, 2006, p. 68).

4 A atividade teatral foi exposta por meio de maquetes com os cenários das peças do Teatro Experimental de Moscou, do Teatro Heroico Experimental e do Teatro da Revolução (CATALOGUE, 1930, p. 679 e 682). 
a tradição é, para a estética assim como para o utilitário, o que nos confere experiência, o que nos permite avançar: a tradição é a base sobre a qual nós devemos nos apoiar para termos os meios de realizar o nosso ideal (MAGNE, 1926, p. 7).

O moderno, nesta perspectiva, não seria "nem a contradição, nem a imitação das expressões anteriores, mas a sua sequência natural" (MAGNE, 1926, p. 8).

As Artes Decorativas, por sua vez, surgiram a partir da criação da Société des Artistes Décorateurs em 1901. Esta associação recebeu o apoio da Union Centrale des Arts Décoratifs (UCAD), o que contribuiu para que a Société pudesse organizar exposições anuais entre 1906 e 1922. No exterior, os seus produtos foram reconhecidos nas exposições universais de Liège (1905), Turin (1911) e Ghent (1913). Foi neste contexto que a Société, junto com a UCAD e a Société d'Encouragement à l'Art et à l'industrie, propôs uma exposição internacional sobre o tema em Paris em 1916, adiada em função da guerra e realizada apenas nove anos depois.

Tratava-se de valorizar "o estudo do objeto por ele mesmo" e "nele mesmo": "esses objetos têm cada um seu programa bem definido pela sua destinação e são completos por eles mesmos" (MAGNE, 1926, p. 10 - 11). Importava não apenas o design de um objeto, mas conferir o devido destaque ao seu processo de realização, valorizando nele o trabalho do artista/artesão.

É dentro deste quadro, em que tradição e modernidade eram vistas como complementares, que o cinema ganhou destaque, como veremos.

\section{O cinema na Exposição Internacional de 1925}

Na classificação dos produtos da Exposição Internacional de 1925, o cinema ainda era associado à fotografia, como "tecnicamente inseparáveis" e pertencendo ao grupo V, a saber, ensino. Apesar do teatro estar no grupo IV (Arts du théâtre, de la rue \& des jardins), os dois - cinema e teatro - foram vistos como expressões artísticas próximas (FRANCE, 1929, p. 9) $)^{5}$.

A ênfase na dimensão educativa deve ser aqui ressaltada. Em primeiro lugar, as escolas municipais parisienses foram chamadas à participação pela prefeitura da cidade (WEISS, 1925, p. 1 - 36). Mobilizar a juventude significava contribuir, como afirma René Weiss, com o "esforço ambicionado por nossa época de criar uma estética nova e de preparar para o futuro" (idem, p. 3), discurso que era a tônica na exposição ${ }^{6}$.

5 Até 1925, o cinema, nas classificações dos produtos existentes nas Exposições Universais, sempre esteve acompanhado da imprensa ou da fotografia, em relação quase de subordinação. A autonomia somente chegou em 1937, quando em outra exposição internacional ocorrida na capital francesa, o cinema foi visto como esfera cultural independente que organiza e transmite a cultura e o conhecimento (MORETTIN, 2013).

6 Nesse contexto foi criada a Cinémathèque de la Ville de Paris (1925), que tinha por objetivo difundir e distribuir filmes juntos às escolas (PASTRE, 2003, p.177 - 186). 
Como recurso educativo, o filme era pensado como importante auxiliar no ensino, percepção que somente seria acentuada ao longo dos anos. Como encontramos na introdução do relatório oficial dedicado à seção em que o assunto foi tratado,

O cinema, pelas novas visões que ele estimula no espírito criador, pelas facilidades que ele aporta à solução de certos problemas técnicos, tais como o estudo do movimento, permite economizar anos de tentativas e de pesquisas. Todo um método de ensino do desenho é baseado no emprego do cinema, demonstração vivaz, que estimula a memória e a imaginação visuais (FRANCE, 1929, p. 9).

Assim pautados, as empresas cinematográficas Gaumont, Sociétés Éclair, Auber e Pathé projetaram, desde a abertura da Exposição, filmes 'instrutivos e documentários', com programação renovada quinzenalmente (RENSEIGNEMENTS, 15 mai 1925, p. 8 - 9). As sessões gratuitas, geralmente acompanhadas por conferencistas, ocorriam todos os dias no grande salão do Congresso do Grand Palais, que tinha capacidade para receber

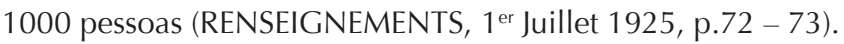

Do ponto de vista expositivo, um estúdio foi reconstruído a fim de mostrar 'a maneira de filmar e a arte de criar os cenários, as visões e as quiromancias, etc.' (RENSEIGNEMENTS,

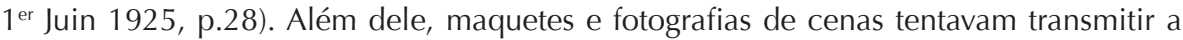
experiência do que era fazer cinema, bem como procuravam demonstrar o seu resultado. Diferentes aparelhos, como alto falantes, amplificadores, microfones, câmeras, projetores e perfuradores, manifestavam o desejo de valorizar a faceta industrial ${ }^{7}$ e, ao mesmo tempo, científica ${ }^{8}$ da atividade.

Os organizadores enfrentaram, em relação a esse aspecto, um problema, pois se deparavam com dificuldades relativas a como expor o cinema em todas as suas dimensões. Como sintetizado no próprio relatório oficial: 'uma arte do movimento não se expõe' (FRANCE, 1929, p.73) .

O esforço de demonstrar a superioridade do cinema francês no contexto internacional não residia apenas no aspecto expositivo. Os autores do relatório oficial da Exposição, Fernand David - senador, comissário geral da Exposição -, e Paul Léon - comissário adjunto da Exposição -, na parte dedicada à descrição da classe e do grupo ao qual a atividade cinematográfica estava vinculada, discorreram sobre a sua então recente história. Celebrando os trinta anos da projeção de filmes pelos irmãos Lumière, afirmaram:

7 Para ficarmos em um dado trazido pelo relatório oficial da Exposição de 1925, no ano de 1924 o valor das exportações de aparelhos fotográficos e cinematográficos, de películas para filmes e filme para fotos (papiers photographiques) ultrapassou 372 milhões de francos. Dentre os países relacionados como clientes, temos EUA, Bélgica, Inglaterra, Espanha, Tchecoslováquia, Suíça, Japão, Brasil, Alemanha, Itália, Argentina e Canadá (FRANCE, 1929, p. 73).

8 É assim valorizado por Becquerel (1925, p. 100). A relação do que foi exibido está em Catalogue (1930, p. 298 e ss).

9 Mallet-Stevens também fez observações nesse sentido: 'Personagens de cera, personagens imóveis, petrificados. O público, sob a forma de um diorama, assistiu a uma tomada de vista. Francis Jourdain, o arquiteto da classe, conseguiu reunir uma multidão de documentos interessantes: vinhetas, fotos, mas tudo isto evocou o cinema sem o representar realmente. [...] É [...] nas salas de exibição de Paris que será efetivamente 'exposto' o cinema'. (Apud MARIONONE, 2006, p. 72). 
"o cinema é uma descoberta francesa" (idem, p.61). Em sintonia com a busca de pioneirismos, elencam dois aspectos, inéditos, relacionados à Exposição: "pela primeira vez, [o cinema] tem lugar em um relatório de Exposição" (idem, p.61); e "pela primeira vez, o cinema figurava na França em uma exposição internacional" (idem, p.73) ${ }^{10}$.

De fato, há no relatório uma discussão detalhada e conceitual sobre a especificidade do cinema que não encontramos em relatórios de exposições anteriores. Afora a preocupação em explicar o chamado "alfabeto visual" do cinema (idem, p.68 e seguintes), o relatório sinaliza a incorporação do cinema moderno francês, de seus diretores e filmes. Sua produção, teórica e prática, é apreendida como expressão de vitalidade e da diversidade da cultura francesa, aspectos tidos como originais: "nenhum país apresenta tantas divergências, tantas escolas opostas" (idem, p.75). Esta pluralidade é responsável pela energia que propulsiona a arte cinematográfica, já que as fórmulas

somente tiveram força de lei nas épocas de decadência: na vida dos estilos como na dos artistas, a arte sofre uma flutuação perpétua, subindo, chegando a um ponto culminante e descendo novamente para subir outra vez e assim por diante (MAGNE, 1926, p.10) ${ }^{11}$.

Germaine Dulac, Marcel L'Herbier, Abel Gance, Jean Epstein, René Clair e Louis Delluc, importantes teóricos e cineastas do período ${ }^{12}$, foram os responsáveis pelas 'obras-mestras de onde saíram, com tendências frequentemente opostas, os melhores filmes franceses do momento' (FRANCE, 1929, p. 71) ${ }^{13}$. Destaque igual é conferido ao cinema educativo e ao documentário (idem, p. 74), campos em que o cinema francês tinha lugar de relevo.

Dado original, também, foram os ciclos de conferências que discutiram "a história, a evolução, as tendências da arte silenciosa". Dentre os palestrantes, Georges-Michel Coissac fez um apanhado histórico do cinema de 1895 a 1924, L'Herbier "falou dos meios de exprimir a ideia cinematográfica e da técnica", Mallet-Stevens, dos "cenários arquiteturais", Dulac "teve por tema a fotogenia dos aspectos exteriores, a angulação, a luz", Epstein, "a fotogenia dos aspectos interiores, o drama fotogênico", Léon Moussinac discorreu sobre as "tendências do cinema francês" (idem, p. 82). Ou seja, do ponto de vista teórico, com exceção do historiador Coissac, os visitantes da Exposição tiveram

10 Deve ser lembrado aqui que o cinema já havia sido objeto de uma exposição, como a ocorrida em 1924 no Musée Galliera. Do ponto de vista das universais, em 1900, os filmes dos irmãos Lumière tiveram grande destaque, assim como o cinematógrafo gigante, destinado a projeções cotidianas. Sobre o assunto, ver TOULET, 1986, p.179- 209.

11 Magne (1926), como apontamos acima, não estava se referindo ao cinema, mas à discussão entre moderno e tradição na Exposição de 1925. Ele constatou com satisfação que não havia uma fórmula a ser seguida, como indica o trecho citado.

12 Sobre a chamada vanguarda francesa no cinema e suas ideias ver XAVIER, 1978.

13 As fotografias dos cenários de Alberto Cavalcanti para Feu Mathias Pascal e de Fernand Léger e Cavalcanti para L'Inhumaine, ambos de Marcel L'Herbier, foram exibidas na Exposição (Cf. FRANCE, 1929, planches LXXXI, LXXXII e LXXXIII). 
a oportunidade de entrar em contato com os principais autores e ideias da vanguarda francesa, daqueles que defendiam o cinema puro e a fotogenia, a expressão artística unicamente manifesta pela visualidade e movimento ${ }^{14}$.

Seguindo a perspectiva geral que norteava o evento, a da conciliação entre a dimensão estética e o caráter utilitário dos objetos, as palestras seguintes abordavam aspectos que complementariam, na perspectiva de seus organizadores, a atividade cinematográfica. Por exemplo, René Jeanne e René Blum fizeram "um estudo comparado dos cinemas estrangeiros: americano, alemão, sueco, russo, italiano, espanhol, inglês". O papel educativo do cinema ficou a cargo de Luchaire. A. Bruneau se ocupou do ensino artístico, Jean Comandon, um dos nomes mais identificados ao cinema científico, do ensino por meio das imagens. Jean Benoît-Lévy, expoente do cinema educativo, se encarregou de sua técnica, e o empresário Léon Gaumont, da "descoberta do cinema sonoro". A série de conferências foi aberta por Maurice Quentin, "presidente do Conselho Municipal de Paris" entre junho de 1924 e maio de 1925, que proferiu a palestra intitulada: "O cinema, um documento histórico" (idem, p. 82). Enfim, educação, ciência, indústria e história conferem ao cinema essa dimensão complementar e, ao mesmo tempo, vista como necessária e integrante do fenômeno cultural.

\section{O lugar do cinema: artes decorativas?}

No que diz respeito à participação dos cineastas ligados à vanguarda artística do período, como L'Herbier e Dulac, deve ser ressaltado que sua presença pode ser pensada a partir, em primeiro lugar, da união proposta entre arte e indústria, tema da própria Exposição de 1925, como indicamos acima. O cinema, invenção da vida moderna, expressaria plenamente essa simbiose. Por isso, esteve presente em todas as classes, em todas as seções, pois, como o próprio relatório oficial afirmava, "sente-se sua influência secreta na arquitetura, nos adereços, na arte da rua, nos tecidos, no cartaz. Ele está na base desse novo estilo que começamos a batizar 'Exposição de Artes Decorativas'”' (FRANCE, 1929, p. 73).

No que diz respeito à participação soviética, esse discurso que procurava conciliar arte e indústria se casava plenamente com o projeto construtivista. Como encontramos em seu catálogo, o esforço em seu pavilhão era para que sua "indústria artística" pudesse "se misturar aos menores gestos do homem, para que ela armazene o sopro dos menores passos, para que ela se manifeste nos menores detalhes do ordinário". Como princípio, estabelecia-se que

14 Tanto a fotogenia quanto o movimento eram elementos valorizados por estes autores porque permitiam o acesso, como diz Ismail Xavier a propósito do pensamento de Dulac, "às camadas mais profundas da vida, onde está depositada a essência íntima de tudo" (1978, p. 73). Interessava nesta reflexão o esforço analítico de identificação daquilo que corresponderia ao específico cinematográfico e aos seus elementos distintos de outras formas de expressão artística, como o teatro e a literatura. 
todo trabalho deve se tornar libertador, inspirador e criador; é preciso que caiam as barreiras que separam a arte da profissão, é preciso, de fato, que a vida como um todo se torne uma arte, que o homem construtor e o homem artista se confundam inseparavelmente. (KOGAN, 1925, p.11-12).

Esses eixos norteadores nos ajudam a compreender o destaque conferido pelos organizadores da Exposição aos cineastas franceses ligados à vanguarda artística. Cabe resgatar aqui novamente a conferência dada por Marcel Magne a propósito do que encontrou em diversos estandes e mostras:

Os artistas e os industriais parisienses, em tudo o que eles apresentam, dão uma impressão da imaginação, do imprevisto, do qual é impossível não ser tocado, e esta imaginação, este imprevisto são, em geral, cheios de predileção pela pesquisa formal como pela harmonia colorida: os volumes abrigam superfícies simples dando aos seus encontros linhas apuradas, belas matérias colocadas em destaque, características do gosto parisiense (MAGNE, 1926, p.8).

Tratava-se de valorizar o novo, afirmar o nacional e "dar livre carreira às ambições artísticas que se afirmavam com uma amplitude cada vez mais acentuada e que proclamavam todas as sociedades de arte aplicada", como nos diz Paul Vitry (1925, p.6). Assim, é possível entender a assimilação oficial de filmes que, à sua maneira, demonstravam o esforço de "se afastar de todo pastiche e de todo compromisso com os estilos antigos, que, como qualquer negócio e disfarçada sob a cor da retrospectiva, recoloca em cena a velharia e o bric à brac" (idem, p.6) ${ }^{15}$.

L'Inhumaine, de L'Herbier, produzido em 1923, estreou em dezembro do ano seguinte, alguns meses antes, portanto, da abertura da Exposição de 1925. Foi um dos filmes exibidos no decorrer do evento, tendo suas fotos de cena ornamentado as paredes da seção devotada ao cinema ${ }^{16}$. Tinha "por objetivo fortalecer a arte contemporânea francesa na América" e foi concebido "como um resumo, uma síntese, uma amostragem de savoir-faire, de técnicas e da estética Art déco" (MARIONONE, 2006, p. 70). Para chegar à obra que expressasse essa estética, trabalharam nos cenários Alberto Cavalcanti, Claude Autant-Lara, Fernand Léger e Mallet-Stevens, responsável pelas edificações visíveis no filme ${ }^{17}$. O músico Darius

15 Paul Vitry (1925) não está se referindo ao cinema em seu texto, mas suas palavras, aplicadas ao espírito geral da exposição, servem também ao nosso objeto.

16 Em mostra recente ocorrida na Cité de l'architecture et du patrimoine (Paris) dedicada à Art Déco, o filme foi projetado no interior do espaço expositivo ao lado de diversos objetos dedicados a lembrar o estilo em 1925 (BRÉON e RIVOIRARD, 2013).

17 Mallet-Stevens havia, na referida exposição ocorrida no Musée Galliera, se ocupado da arquitetura dos cinemas. Para ele, "de todas as construções que são edificadas em nossos dias, uma sala de cinema é a que deve apresentar a característica a mais moderna" (Apud MARIONONE, 2006, p. 68). Em sintonia com o discurso das vanguardas artísticas da época, recuperava um conceito caro aos seus pensadores, o da fotogenia, para afirmar, em outro momento, que "a arquitetura moderna (...) é essencialmente fotogênica" (FRANCE, 1929, p. 78). 
Milhaud compôs a trilha sonora. Como afirma Marionone, L'Inhumaine é um "filme Art déco por excelência" e "traz nele a inspiração da futura exposição de 1925" (2006, p. 70).

Não à toa este filme foi um dos escolhidos para representar o cinema moderno francês em detrimento de obras mais agressivas, como Ballet Mécanique (1924), de Léger. No trabalho de L'Herbier, os objetos de cena e cenários dialogam com o universo Art Déco acima mencionado. O filme é um escancarado melodrama, bem tradicional no que diz respeito a enredo e atuação das personagens. Sua sinopse reforça essa filiação ao gênero: assistimos a história de uma diva, Claire Lescot, interpretada pela cantora e atriz Georgette Leblanc, rodeada por um sem-número de pretendentes. Um deles, desgostoso e ressentido com o fato de ser preterido por um jovem cientista, planeja sua vingança: envia-lhe flores e, no meio delas, uma serpente venenosa. Picada e ferida mortalmente, ela é levada ao laboratório de seu amado, que consegue ressuscitá-la após submetê-la aos efeitos de sua poderosa máquina. Nada mais folhetinesco, portanto.

Todavia, o momento catártico, que é o da ressurreição da amada, é trabalhado de forma a salientar os efeitos visuais: luzes são lançadas e se alternam sobre o cenário, o cientista e seus ajudantes; planos de pêndulos e de maquinarias se sobrepõem; velozes movimentos de câmera acentuam o ritmo acelerado da montagem; planos curtos que apresentam ou detalhes das personagens ou dos equipamentos; imagens que não podem ser ligadas a nenhum objeto de cena e/ou ator. Tudo dirigido no sentido de reforçar o caráter abstrato das imagens, salientando o que está escrito no letreiro: "como em uma sinfonia do trabalho".

Ao final desta sequência, Lescot revive, e o jovem cientista declara o seu amor por ela e pela humanidade. Melodrama, art déco e experimentação convivem de forma exemplar nessa obra que tão bem expressou o princípio norteador da Exposition Internationale des Arts Décoratifs et Industriels Modernes: a convivência entre tradição e modernidade.

No tocante à cinematografia estrangeira, Suécia, Itália, Grã-Bretanha e Dinamarca ${ }^{18}$, países ou com indústrias cinematográficas consolidadas ou com uma filmografia de referência para o momento, não enviaram seus aparelhos ou seus filmes para a exposição. Além da França, apenas a URSS participou da "exposição da cinematografia". A cinematografia russa estava "representada por quadros extraídos de diferentes filmes, notadamente Palais \& Citadelle, D'une Étincelle naît la Flamme, dirigido por Bassalygo, Le Minaret de la Mort, A Greve, realizado por Eigenstein (sic), Aelita, de Protazanov'" (MARIONONE, 2006, p. 85) $)^{19}$.

$\mathrm{O}$ quadro de premiações procurou atender à diversidade acima mencionada. L'Herbier e Dulac, por exemplo, receberam diplomas de honra. Mesmo considerando que uma premiação deste tipo procurava também atender à diplomacia, não deixa de ser curioso que Eisenstein figure nesta lista por ter recebido uma medalha de ouro ${ }^{20}$.

18 Devemos lembrar mais uma vez que Alemanha e Estados Unidos não participaram da Exposição.

19 Há também a referência à participação de Kino-Glaz, de Dziga Vertov (EXPOSITION, 1925, p. 73). Alguns dos filmes citados no trecho acima puderam ser identificados: de Dmitri Bossalygo, Iz iskry plamya (1924); Le Minaret de la Mort é de 1925 e foi dirigido por Viacheslav Viskovskii, "primeiro filme oriental realizado na URSS" (DRIEU, 2013, p. 95). Eigenstein é, na verdade, Eisenstein.

20 A lista completa dos prêmios da classe em que se encontrava o cinema pode ser consultada em EXPOSITION, 1926, p. 71 e ss. 
Esta premiação, porém, não significava que o cinema ocupasse para a União Soviética o papel de principal embaixador. Estavam à frente a literatura, o teatro construtivista, as artes gráficas e a arquitetura, como vimos, na tarefa de "auxiliar a tornar a URSS conhecida" 21 .

Apesar do percurso acima traçado, certos setores ficaram insatisfeitos com o espaço ocupado pelo cinema, considerado modesto e tímido ${ }^{22}$, uma "localização minúscula". Havia a expectativa de que um palácio dedicado ao cinema fosse construído, pavilhão a ser idealizado por Mallet-Stevens (MARIONONE, 2006, p.72).

Por outro lado, entendia-se que o cinema deveria constar da 'nomenclatura oficial das diversas indústrias representadas' na Exposição (PIERRETTE, 1925). De acordo com um articulista, o novo meio de comunicação

merecia um pavilhão como o do Livro, o da Mobília ou o da Imprensa, pois não é ele o feixe luminoso no qual colaboram o Pensamento, o Artista e o Artesão? Não é ele a vivaz e constante imagem de tudo aquilo que nos circundou ou nos circunda e que toca nas diversas manifestações do Espírito e da mão de obra do Homem que se teve o prazer de agrupar nesta exposição? (PIERRETTE, 1925)

Mereceria, enfim, ser entendido "como grande difusor do Pensamento universal" (idem, 1925).

Tais demandas somente foram atendidas plenamente em 1937, com a Exposition Internationale des Arts et Techniques dans la vie moderne, momento em que as disputas simbólicas já não serão mais restritas ao espaço expositivo, ganhando terreno o conflito bélico que levará o mundo ao abismo.

Eduardo Victorio Morettin é professor de História do Audiovisual na ECA-USP.

eduardomorettin@usp.br

\section{Referências}

BECQUEREL, Paul. La Science. Exposition internationale des Arts décoratifs et industriels modernes. Paris: I'Art vivant, Larousse, 1925, 100p.

BRÉON, Emmanuel. L'Exposition des arts décoratifs. In: Vários autores. Création et vie artistique: au temps de l'exposition de 1925. [Paris]: Centre national de documentation pédagogique, 2006, pp. $16-35$.

21 Título parcial do texto de Kameneff (1925, p. 9 - 14). Neste livro de quase cem páginas, em que encontramos textos de figuras importantes da intelectualidade russa, como Anatoly Lunatcharsky, então à frente da Instrução Pública de seu país, nenhuma referência há ao cinema.

22 A expressão que encontramos no relatório oficial a respeito desta participação foi "tão timidamente representada no Grand Palais" (FRANCE, 1925, p. 73). 
BRÉON, Emmanuel; RIVOIRARD, Philippe (dirs). 1925. Quand I'Art Déco séduit le monde. Paris: Éditions Norma e Cité de l'architecture et du patrimoine, 2013.

BRUNHAMMER, Yvonne. Les Années 25, collections du Musée des arts décoratifs. Paris: Musée des arts décoratifs, 1966.

Catalogue général officiel. Exposition internationale des arts décoratifs et industriels modernes, Paris, avril-octobre 1925. Paris: Impr. de Vaugirard, [1930].

DRIEU, Cloé. Fictions nationales. Cinéma, empire et nation en Ouzbékistan (1919 - 1937). Paris: Éditions Karthala, 2013.

Exposition internationale des arts décoratifs et industriels modernes. Section de I'U.R.S.S. Académie des sciences de l'art. Catalogue des œuvres d'art décoratif et d'industrie artistique exposées dans le pavillon de I'U.R.S.S. Au Grand Palais et dans les galeries de I'Esplanade des Invalides. Paris: Impr. Kapp, 1925.

. Paris 1925. Liste des récompenses. Paris: Impr. des journaux officiels, 1926.

France. Ministère du Commerce, de l'Industrie, des Postes et des Télégraphes. Exposition internationale des arts décoratifs et industriels modernes, Paris, 1925. Rapport général. Section Artistique et Technique. Volume X. Théâtre, Photographie et Cinématographie. Paris : Librairie Larousse, 1929.

HUHN, Rosi. Art et technique: la lumière. In: Paris 1937: cinquantenaire de l'Exposition internationale des arts et des techniques dans la vie moderne: [exposition, Musée d'art moderne de la Ville de Paris, 13 mai-30 août 1987]. Paris: Institut français d'architecture: Paris-musées, 1987, pp. 392 - 403.

KAMENEFF, O. D. L'Exposition de Paris doit aider à faire connaître I'U.R.S.S. In: Exposition internationale des arts décoratifs et industriels modernes. Section de I'U.R.S.S. L'art décoratif et industriel de I'U.R.S.S. Moscou: Édition de la comite de la section de I'U.R.S.S., 1925, pp. 9 - 14.

KOGAN, P. Préface. In: Exposition internationale des arts décoratifs et industriels modernes. Section de I'U.R.S.S. L'art décoratif et industriel de I'U.R.S.S. Moscou: Édition de la comite de la section de I'U.R.S.S., 1925, pp. 12 e 11.

MAGNE, Henri-Marcel. Les Enseignements de I'Exposition internationale des arts décoratifs et industriels modernes. Conférence faite le 29 octobre 1925 par M. H.-M. Magne. Paris: L. Eyrolles, 1926.

MANIER, Alain. Des années folles? In: BRÉON, E.; ESCANDE, D.; LOUPIAC, C.; MANIER, A. e MARIONONE, I. Création et vie artistique: au temps de l'exposition de 1925. [Paris]: Centre national de documentation pédagogique, 2006, pp. 6 - 16 .

MARIONONE, Isabelle. Le cinéma, un esprit nouveau. In : BRÉON, E.; ESCANDE, D.; LOUPIAC, C.; MANIER, A. e MARIONONE, I. Création et vie artistique: au temps de l'exposition de 1925. [Paris]: Centre national de documentation pédagogique, 2006, pp. 65 - 77.

MORETTIN, E. Uma construção luminosa: o cinema e a Exposição Internacional de 1937. Revista Estudos Históricos. v. 26, n. 51, ago. 2013, pp. 73 - 93.

OLIVEIRA, Vanessa Teixeira de. Eisenstein ultrateatral. Movimento expressivo e montagem de atrações na teoria do espetáculo de Serguei Eisenstein. São Paulo: Perspectiva, 2008.

PASTRE, Béatrice de. Une archive dédiée à la pédagogie du cinema. 1895. Mille huit cent quatrevingt-quinze. Paris, v. 41, 2003, pp. 177 - 186.

PIERRETTE. Le Cinéma a l'Exposition des Arts Décoratifs. Journal illustré des arts décoratifs et industriels modernes Exposition internationale de 1925. Paris, n. 4, 1er Juillet 1925, página não numerada

Renseignements utiles. Journal illustré des arts décoratifs et industriels modernes Exposition internationale de 1925. Paris, n. 1, 15 mai 1925, pp. 8 - 9. 
. Journal illustré des arts décoratifs et industriels modernes Exposition internationale de 1925. Paris, n. 2, 1 er Juin 1925, p. 28 - 29.

Journal illustré des arts décoratifs et industriels modernes Exposition internationale de 1925. Paris, n. 4, 1 er Juillet 1925, p. $72-73$

ROMOFF, Serge. Le Pavillon de I'U.R.S.S. In: Exposition internationale des arts décoratifs et industriels modernes. Section de I'U.R.S.S. Académie des sciences de l'art. Catalogue des œuvres d'art décoratif et d'industrie artistique exposées dans le pavillon de I'U.R.S.S. Paris : I'Art vivant, Larousse, 1925, pp. $125-126$.

TOULET, E. Le Cinéma à l'exposition universelle de 1900. Revue d'Histoire Moderne et Contemporaine. Paris, n. 33, 1986, pp. 179 - 209.

WEISS, René. La Participation de la Ville de Paris à l'Exposition internationale des arts décoratifs et industriels modernes. Paris: Imprimerie Nationale, 1925.

VITRY, Paul. L'Exposition Internationale des Arts Décoratifs et Industriels Modernes - Introduction. In: JANNEAU, Guillaume e BENOIST, Luc. L'Exposition internationale des arts décoratifs et industriels modernes. Paris: Publications de "Beaux-Arts", 1925, pp. 1 - 7.

XAVIER, Ismail. Sétima Arte: um culto moderno. São Paulo, Perspectiva/Secretaria da Cultura, Ciência e Tecnologia do Estado de São Paulo, 1978. 